\title{
Stabilization of Calibration Metrological Characteristics of Technological Inspection Tools
}

\author{
Petrovsky Eduard, Bukhtoyarov Vladimir, Savitskaya Svetlana \\ Department of Technological Machines and Equipment for Oil and Natural Gas Industry \\ Siberian Federal University \\ Krasnoyarsk, Russia
}

\begin{abstract}
The paper presents analysis of the results of template 873 measurements which is a tool used for inspection in wagon depo. The data obtained were analyzed to confirm the stability of inspection results. It was shown that the measurement and determination of the final result by calculating the average value causes misleading results. Also random factors which affect measurements are presented. The subjective factor in this process is from the calibrator. To make measurement process more stable we need to reduce the effect of these factors. One of the ways to improve measurement process and make it more stable is its automatization. Improving the accuracy of measurements is one of the main objectives concerning this issue.
\end{abstract}

Keywords - metrological support, calibration, automatization, tolerance, measurement, variation.

\section{INTRODUCTION}

Measurement data are collected during process of metrological maintenance. These data can be represented either in paper or digital form in a database. These options depend on how particular company uses modern software products. When working with these data it is advisable to use a statistical processing. This allows you to assess the following [1-4]:

- stability of the production process at the time of template verification / calibration;

- the stability of the production process of verification / calibration as a whole;

- situations when controlled process parameters exceeds tolerance.

\section{EXPERIMENTAL STUDY}

Object of measurements: Kholodov template (template 873), which is designed to test the coupler during maintenance of wagons (Fig. 1).

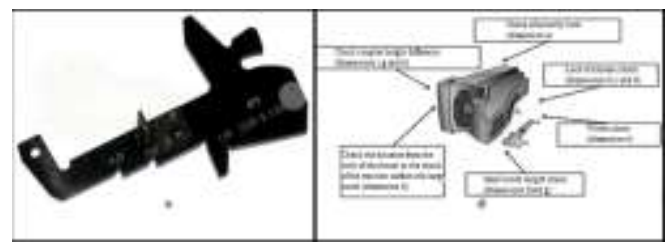

Fig. 1. Template 873(a); coupler parameters, inspected using template 873 (b)
The dimensions of template 873 which are estimated during calibration are presented in the Fig.1.

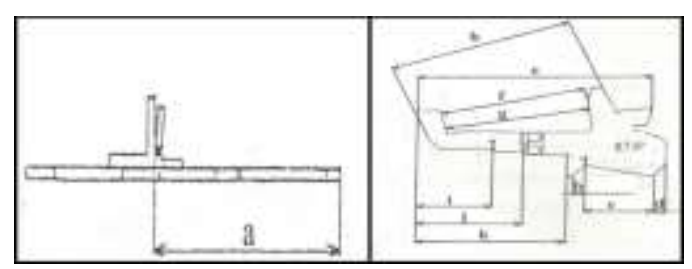

Fig. 2. Verified calibrations dimensions of template 873

This dimensions are used to inspect the following parameters of auto coupler: security lock; the thickness of the lock; the width of the throat; small tooth length; distance from the wall of the pharynx to the shock of the traction surface of a large tooth; difference of coupler parts height. Verified dimensions tolerance is shown in Table 1.

TABLE I. TEMPLATE 873 DIMENSION CALIBRATION TOLERANCE

\begin{tabular}{|c|c|c|c|c|c|}
\hline \multicolumn{2}{|c|}{ Verified } & \multirow{2}{*}{ Symbol } & \multirow{2}{*}{$\begin{array}{c}\text { Tolerance, } \\
\text { mm }\end{array}$} & \multicolumn{2}{|c|}{$\begin{array}{l}\text { Dimension } \\
\text { limits, } \mathbf{m m}\end{array}$} \\
\hline parameter & $\begin{array}{c}\text { dimension, } \\
\mathrm{mm}\end{array}$ & & & $\min$ & $\max$ \\
\hline $\begin{array}{l}\text { Check of } \\
\text { security lock }\end{array}$ & 98 & a & $-0,5 \ldots+0,2$ & 97,5 & 98,2 \\
\hline \multirow{3}{*}{$\begin{array}{l}\text { thickness of } \\
\text { the lock }\end{array}$} & 6 & $\mathrm{~b}$ & $\pm 0,1$ & 5,9 & 6,1 \\
\hline & 45,5 & $\mathrm{c}$ & $\pm 0,1$ & 45,4 & 45,6 \\
\hline & 7,5 & $\mathrm{~d}$ & $\pm 0,18$ & 7,32 & 7,68 \\
\hline $\begin{array}{l}\text { width of the } \\
\text { throat }\end{array}$ & 155 & $\mathrm{e}$ & \multirow{7}{*}{ $\pm 0,2$} & 154,8 & 155,2 \\
\hline \multirow{2}{*}{$\begin{array}{l}\text { small tooth } \\
\text { length }\end{array}$} & 98 & $\mathrm{f}$ & & 97,8 & 98,2 \\
\hline & 97 & $\mathrm{~g}$ & & 96,8 & 97,2 \\
\hline $\begin{array}{l}\text { distance } \\
\text { from the } \\
\text { wall of the } \\
\text { pharynx to } \\
\text { the shock of } \\
\text { the traction } \\
\text { surface of a } \\
\text { large tooth }\end{array}$ & 125 & $\mathrm{~h}$ & & 124,8 & 125,2 \\
\hline \multirow{3}{*}{$\begin{array}{l}\text { difference of } \\
\text { coupler } \\
\text { parts height }\end{array}$} & 50 & $\mathrm{i}$ & & 49,8 & 50,2 \\
\hline & 70 & $\mathrm{j}$ & & 69,8 & 70,2 \\
\hline & 100 & $\mathrm{k}$ & & 99,8 & 100,2 \\
\hline
\end{tabular}

Template 873 validation assumes a threefold measuring process of its dimensions. Measurements were carried out by two calibrators (A and B) using microscope under laboratory conditions. Results obtained during calibration are presented in Table 2. 
TABLE II. MEASUREMENTS DISTRIBUTION AND ESTIMATED MEAN VALUES

\begin{tabular}{|c|c|c|c|c|c|c|c|c|}
\hline \multirow[b]{2}{*}{$\begin{array}{c}\text { Inspected } \\
\text { dimension, } \\
\text { mm }\end{array}$} & \multicolumn{4}{|c|}{ Calibrator A } & \multicolumn{4}{|c|}{ Calibrator B } \\
\hline & $\begin{array}{c}\text { First } \\
\text { measurement, } \\
\text { mm }\end{array}$ & $\begin{array}{c}\text { Second } \\
\text { measurement, } \\
\text { mm }\end{array}$ & $\begin{array}{c}\text { Third } \\
\text { measurement, } \\
\text { mm }\end{array}$ & $\begin{array}{c}\text { Mean } \\
\text { value, mm }\end{array}$ & $\begin{array}{c}\text { First } \\
\text { measurement, } \\
\text { mm }\end{array}$ & $\begin{array}{c}\text { Second } \\
\text { measurement, } \\
\text { mm }\end{array}$ & $\begin{array}{c}\text { Third } \\
\text { measurement, } \\
\text { mm }\end{array}$ & $\begin{array}{c}\text { Mean } \\
\text { value, mm }\end{array}$ \\
\hline $\mathrm{a}$ & 98,053 & 97,987 & 98,085 & 98,042 & 98,038 & 98,003 & 97,998 & 98,013 \\
\hline $\mathrm{b}$ & 5,901 & 5,988 & 5,991 & 5,960 & 6,012 & 6,097 & 6,008 & 6,039 \\
\hline $\mathrm{c}$ & 7,511 & 7,553 & 7,532 & 7,532 & 7,495 & 7,512 & 7,518 & 7,508 \\
\hline $\mathrm{d}$ & 45,503 & 45,511 & 45,507 & 45,507 & 45,510 & 45,523 & 45,518 & 45,517 \\
\hline $\mathrm{e}$ & 155,145 & 155,186 & 155,202 & 155,178 & 155,184 & 155,193 & 155,195 & 155,191 \\
\hline $\mathrm{f}$ & 97,803 & 97,946 & 97,909 & 97,886 & 97,988 & 97,992 & 97,989 & 97,990 \\
\hline $\mathrm{g}$ & 96,900 & 96,923 & 96,983 & 96,935 & 97,178 & 97,105 & 96,977 & 97,087 \\
\hline $\mathrm{h}$ & 124,981 & 124,963 & 124,973 & 124,972 & 125,097 & 125,058 & 125,076 & 125,077 \\
\hline $\mathrm{i}$ & 50,206 & 50,188 & 50,106 & 50,167 & 50,183 & 50,191 & 50,146 & 50,173 \\
\hline $\mathrm{j}$ & 70,146 & 70,183 & 70,198 & 70,176 & 70,213 & 70,198 & 70,202 & 70,204 \\
\hline $\mathrm{k}$ & 100,203 & 100,173 & 100,207 & 100,194 & 100,187 & 100,148 & 100,167 & 100,167 \\
\hline
\end{tabular}

The result of calculating the arithmetic mean of the values recorded in the calibration certificate. The resulting value must be within tolerance. As a result of calibrator $\mathrm{B}$ measurement the average value of dimension " $i$ " is $0,004 \mathrm{~mm}$ beyond the pre-efficient advice controlling size. As it can be seen there is no repetition of values of measuring dimension "a". Therefore, these events equiprobable and do not obey the normal distribution law. The average value of " $\mathrm{j}$ " during the calibrator B measurement (4th, 5th, 6th measurements) is out of range measurements. As a result calibrator A recognizes that the template 873 fit for use, and calibrator B recognizes that the same template does not fit.

During the second part of the experimental study template was measured by calibrator $\mathrm{C}$. The measurement was made for dimension " $\mathrm{j}$ ". The results are presented in the Table 3.

TABLE III. CALIBRATOR C MEASUREMENTS OF DIMENSION “J"

\begin{tabular}{|c|c|c|}
\hline $\begin{array}{c}\text { Measurement 1, } \\
\text { mm }\end{array}$ & $\begin{array}{c}\text { Measurement } \\
\mathbf{2 , m m}\end{array}$ & $\begin{array}{c}\text { Measurement 3, } \\
\mathbf{m m}\end{array}$ \\
\hline 70,186 & 70,189 & 70,189 \\
\hline
\end{tabular}

In Fig. 3 a diagram of values of dimension «j» measured by three calibrators is shown. The chart also contains a trend line showing the change obtained values. Calibrator $\mathrm{C}$ scatter measurements less than calibrators A and B. Let us analyze the results of dimension $\langle\mathrm{j}\rangle$ measurements.

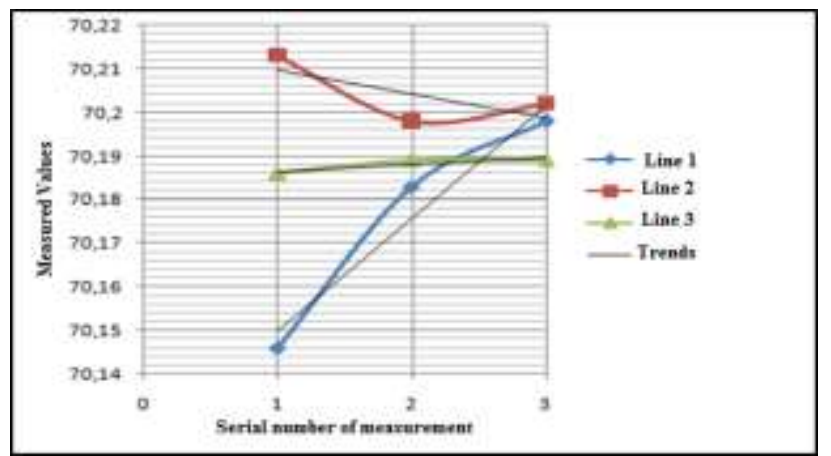

Fig. 3. Measurements of dimension "j" (Line 1 - measured by calibrator A; Line 2 - measured by calibrator B; Line 3 - measured by calibrator $\mathrm{C}$ and estimated trends)
TABLE IV. MEASUREMENTS OF DIMENSION “J”

\begin{tabular}{|c|c|c|c|c|c|}
\hline 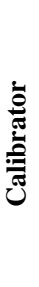 & 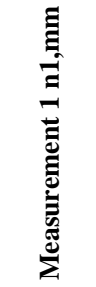 & 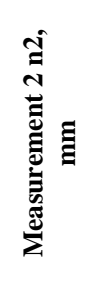 & 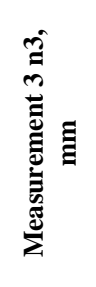 & 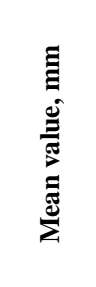 & 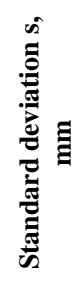 \\
\hline A & 70,146 & 70,183 & 70,198 & 70,176 & 0,027 \\
\hline B & 70,213 & 70,198 & 70,202 & 70,204 & 0,008 \\
\hline $\mathrm{C}$ & 70,186 & 70,189 & 70,189 & 70,188 & 0,002 \\
\hline
\end{tabular}

The mean and standard deviation of the measurements are specified in Table 4. The standard deviation measurement is an indicator of variability. Standard deviation indicates how widely values are dispersed from the average.

$$
s=\sqrt{\frac{\sum_{i=1}^{n}\left(x_{i}-x_{i n}\right)^{2}}{n-1}}
$$

here $\mathrm{s}$ is standard deviation; $\mathrm{n}$ - number of measurements performed by calibrator; $x_{i}$ - single measured value; $x_{c p}$ - the average value of measurements performed by calibrator. The closer to zero the standard deviation the more reliable the average. Calibrator $\mathrm{C}$ measurements are more precise then measurements performed by calibrator $\mathrm{A}$ and $\mathrm{B}$.

Consequently, the mean value is not always valid to evaluate the data distribution. Calculation of the standard deviation while processing calibration results is important. Limiting the calculations to use only average values gives incorrect results when obtaining the calibration.

On the basis of the measurement results it can be said that the process of measuring the template 873 is random. Since the measurement process is random, then the definition of the resulting value by calculating the mean value of the measured values is misleading. 


\section{DISCUSSION}

It was shown that we obtained different results during measurement procedures executed by different calibrators with the same measurement tools and the same verified template. Such variations are caused by random scatter of values. It is obvious that measurement process cannot be stabilized in specific laboratory conditions without defining random factors [4-9].

In the process of measuring the estimated values are affected by random factors (see Fig. 4). So it is necessary to determine how these factors affect on this process.

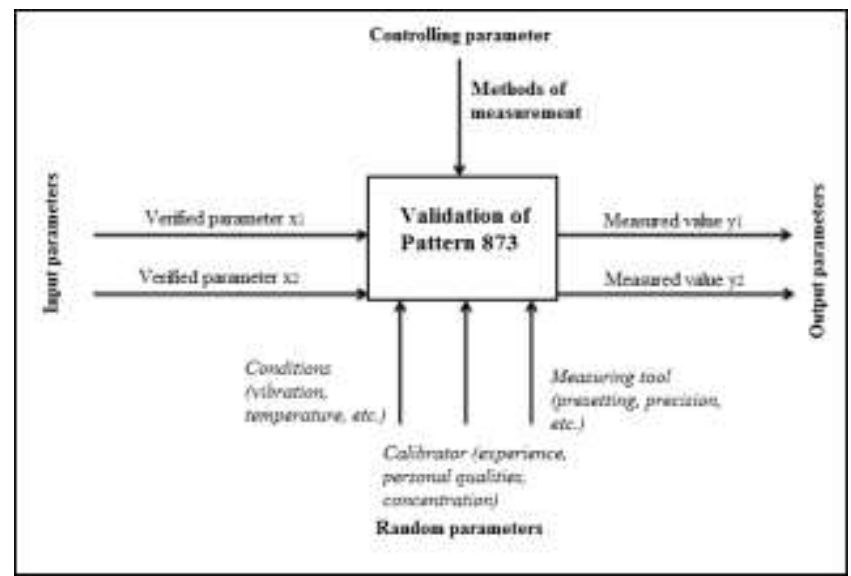

Fig. 4. The input, output, control and random parameters of the measuring process template number 873

We suppose that calibrator is a subjective factor during measurement. If the measurement is not affected by random parameters, we can say that measured values of dimensions are functions of its real values:

$$
Y_{n}=F_{n}\left(x_{n}\right) .
$$

But in our case measurements are also affected by the other factors:

$$
Y_{n}=F_{n}\left(x_{n}, u_{n \text { controlled }}, u_{n \text { random }}\right),
$$

Here $u_{n}$ controlled are factors from measurement procedure; $u_{n}$ random are factors from the environment, calibrators and measurement tools.

To obtain stable measurements, it is necessary to minimize the impact of these factors [10-13]. One of the ways to stabilize the technological process is automated measurements. Abstract model of measurement automation is shown in Fig. 5.

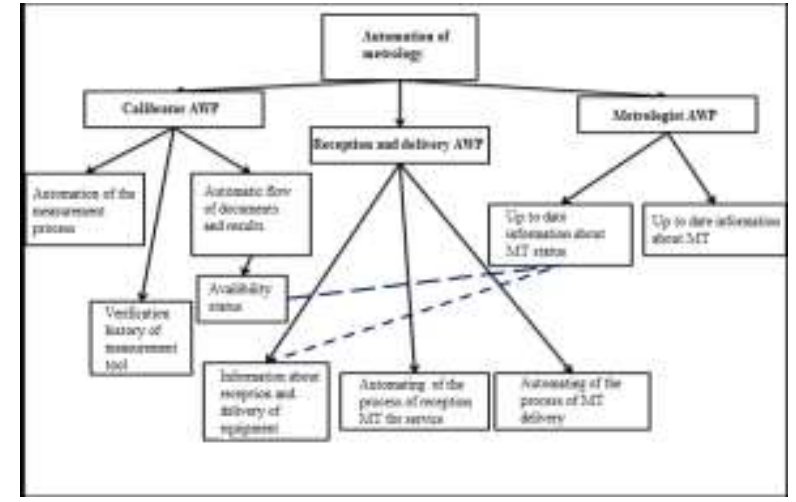

Fig. 5. Abstract model of metrology automation

Automated metrology activities is presented in the form of an integrated system consisting of a synthesis of the required workstations, which allow real-time to receive the necessary information about the status of the measurement tools [14].

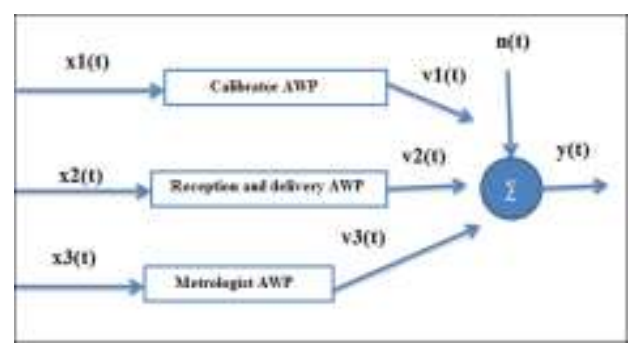

Fig. 6. Signal distribution in measurement system with multiple automated workplaces (AWP)

Fig. 6 shows the distribution of several different forms of signals, the outputs of which are summed and produce a single output signal which is fed directly to the client making the request. The number of sources from which you receive information may be arbitrary.

Each source carries its relative contribution to the output power and the corresponding delay in each AWP. This model is described by an equation based on a (2) [14]:

$$
y(t)=\alpha_{1} x_{1}\left(t-\tau_{1}\right)+\alpha_{2} x_{2}\left(t+\tau_{2}\right)+\alpha_{3} x_{3}\left(t+\tau_{3}\right)+n(t)
$$

Here $\alpha_{1}$ is permanent attenuation coefficient in each AWP and $\tau_{1}$ is corresponding delay in each AWP. From this equation signal delay and its evaluation will depend on the success of this system [15-16].

Automatically receive the results possible with existing hardware designed for measuring information. General view of the component parts listed in Fig. $7(x(t, \Theta)$ - the measurement object; $\mathrm{u}(\mathrm{t})$ - an electrical signal; $\eta(t)$ - a sampling operation; $L(t)$ - coding; $\hat{\beta}(t)$ - getting results). 


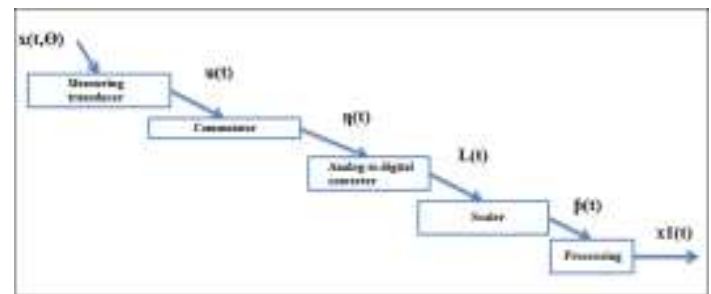

Fig. 7. General view of measuring and computing channel for calibrator AWP

Signal delay may occur during processing because it takes time for the algorithm to produce a result.

Today AWP Metrology, with a limited number of functions given is on the market. However, there is a need to develop industry-specific solutions to make such software-hardware tool and make specific measurement processes more stable.

\section{SUMMARY}

Stabilization of the measurement process is beyond the scope of the calibrator and the accuracy of measurements. Fig. 8 shows a tree of goals, affecting the enterprise level [17-20].

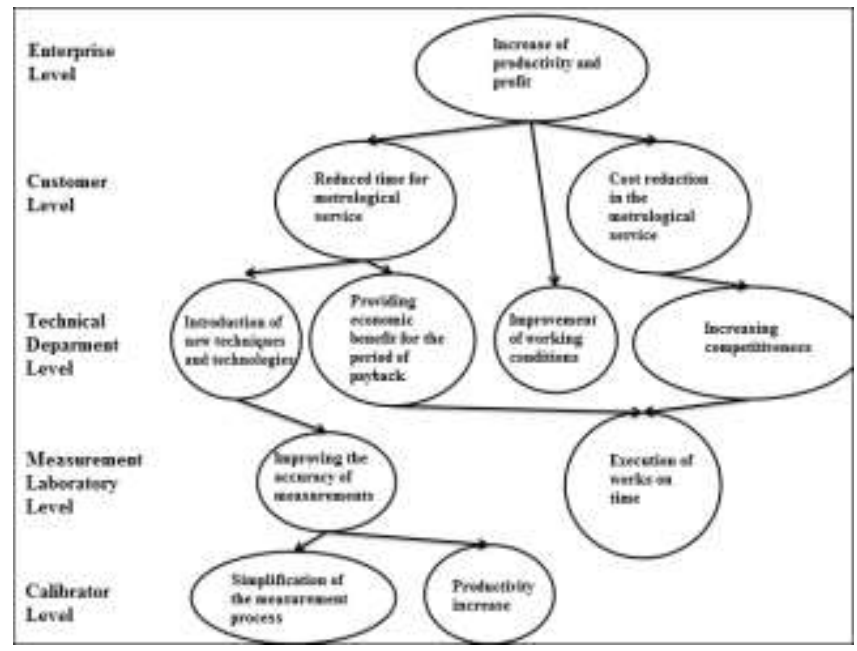

Fig. 8. Tree of goals in the automation of the measurement process

Measurement process stability can be provided by automation which makes it possible to reduce the impact of a large number of random factors.

\section{REFERENCES}

[1] Grigoriev, S. N., Teleshevskii, V. I., Glubokov, A. V., Ped', S. E., \& Glubokova, S. V. (2012). The problems of metrological support for the preparation of production in machine construction. Measurement Techniques, 1-4.

[2] Taymanov R., Sapozhnikova K., Druzhinin I. Sensor devices with metrological self-check //Sensors \& Transducers, 2011, vol. 10, pp. 30.
[3] Marciniec A., Budzik G., Dziubek T. Automated measurement of bevel gears of the aircraft gearbox using GOM //Journal of KONES, 2011, vol. 18, pp. 259-264.

[4] Petrovskiy, E. A., Buryukin, F. A., Bukhtiyarov, V. V., Savich, I. V., \& Gagina, M. V. The FMEA-Risk Analysis of Oil and Gas Process Facilities with Hazard Assessment Based on Fuzzy Logic. Modern Applied Science, 2015, vol. 9(5), pp. 25-31.

[5] El'rikh Yu.V., Petrovsky E.A. The application of risk-management methods aimed to optimize maintenance programs. Europaische Fachhochschule, 2013, vol. 4(2), pp. 146-148.

[6] Elrikh Y.V., Petrovsky E.A. Optimization of repair programs for electric power companies. Applied Sciences and technologies in the United States and Europe: common challenges and scientific findings Papers of the 2nd International scientific conference, 2013, pp. 136-139.

[7] Fujimoto H., Abe M., Osawa S. Development of Dimensional X-Ray Computed Tomography (Special Issue on Laser Metrology for Precision Measurement and Inspection in Industry) //International journal of automation technology, 2015, vol. 9, №. 5, pp. 567-571.

[8] Martin J. Metrology automation is here and now: robots and laser trackers are changing the landscape in manufacturing //Quality, 2014, vol. 53, №. 4, C pp 28-33.

[9] Gronle M. et al. itom: an open source metrology, automation, and data evaluation software //Applied optics, 2014, vol. 53(14), pp. 2974-2982.

[10] Yang H. C., Tieng H., Cheng F. T. Automatic virtual metrology for wheel machining automation //International Journal of Production Research, 2015

[11] Bauer J. M. et al. Development Trends in Automation and Metrology //IFAC-PapersOnLine, 2015, vol. 48, №. 24, pp. 168-172.

[12] Müller B. Automatization of Acceptance Test for Metrology Algorithms //Proceedings of the International Conference on Software Engineering Research and Practice (SERP), The Steering Committee of The World Congress in Computer Science, Computer Engineering and Applied Computing (WorldComp), 2015, pp. 84.

[13] Pal B., Ahmad S., Govil A. K. Automation and evaluation of two different techniques to calibrate precision calibrators for low frequency voltage using thermal devices //Mapan, 2013, vol. 28, №. 1, pp. 31-36.

[14] Sładek J. A. Coordinate Metrology: Accuracy of Systems and Measurements, Springer, 2016.

[15] Zhu Z. et al. Automatic Three-Dimensional Measurement of LargeScale Structure Based on Vision Metrology//The Scientific World Journal, 2014, vol. 2014.

[16] Szewczyk R., Zieliński C., Kaliczyńska M. (ed.). Progress in Automation, Robotics and Measuring Techniques: Volume 3 Measuring Techniques and Systems, Springer, 2015, vol. 352

[17] Jamshidi J. et al. Manufacturing and assembly automation by integrated metrology systems for aircraft wing fabrication //Proceedings of the Institution of Mechanical Engineers, Part B: Journal of Engineering Manufacture, 2010, vol. 224, №. 1, pp. 25-36.

[18] Muelaner J. E., Cai B., Maropoulos P. G. Large-volume metrology instrument selection and measurability analysis //Proceedings of the Institution of Mechanical Engineers, Part B: Journal of Engineering Manufacture, 2010, vol. 224(6), pp. 853-868.

[19] Hocken R. J., Pereira P. H. (ed.). Coordinate measuring machines and systems, CRC Press, 2011.

[20] LIN G., ZHOU S. Evaluation of Measurement Error for the Calibration System of Electronic Current Transformer [J] //Electrical Measurement \& Instrumentation, 2010, vol. 6, pp. 010 